\title{
On the Coordinated Development of the Commerce Circulation and Regional Economy from the Perspective of Symbiosis
}

\author{
Jing Xian \\ Shaanxi Institute of International Trade \& Commerce; Xi'an 712046 China
}

Keywords: Symbiotic concept; commerce circulation; regional economy.

\begin{abstract}
With the rapid economic development, the commerce circulation has increasingly become an important factor in promoting the rapid economic development in our country. Regional commerce circulation has promoted the flow of capital in a certain region and accelerated the mutual cooperation of favorable resources in the region. It is of great significance to improve the economic structure and change the form of industrial organization and then promote the relatively rapid development of the regional economy. Through the study and analysis of symbiosis concept, this paper elaborated the synergetic development of commerce circulation and regional economy, analyzed the promotion of advanced commerce circulation development to the development of regional economy, and finally proposed a series of suggestions for the symbiotic development of commerce circulation and regional economy, hoping to offer an important reference to enhance the economic competitiveness of our country.
\end{abstract}

\section{Introduction}

The importance of the regional economy has become increasingly prominent with the acceleration of the current global economic integration. The modern commerce circulation industry plays an important role in improving inter-regional capital flow and product output, and thus will greatly promote the development of the regional economy. At the same time, a good-quality regional commerce circulation will also promote the maximum optimization of the industrial structure in the region, establish an industrial pattern and a logistic pattern that meets the requirements of the modern economy, and thereby better exert the synergy of the development of the commerce circulation and the regional economy. It plays an important role in promoting the overall economic development in the region to analyze the realistic significance of the coordinated development of the commerce circulation and the regional economy from the perspective of symbiosis. The realization of the symbiotic relationship between the regional economy and the commerce circulation is of great significance to the planning of the regional economy development and the achievement of rapid economic growth.

\section{An Overview of the Symbiotic Mechanism}

The concept of symbiosis contains three elements: symbiotic unit, symbiotic mode and symbiotic environment. From the behavior of the symbiotic relationship, it contains various relationships, such as parasitism, mutualism, and so on. Economic symbiosis arises from economic organizations, governments and enterprises which are with similar or different scales in nature and size, and they have interaction and harmonious development in the same symbiotic environment. In general, the symbiotic economy is also divided into two categories, namely sharing-type complementation and competition-type complementation. The former mainly refers to that two parties or more parties in the symbiosis system share resources, magnify the economic influence and then promote the development of different members in the system. The latter is a link in an economic unit formed by the overall competition. At the same time, however, competitors are also mutually beneficial in the cooperation field, thus creating a pattern of disequilibrium between symbiotic economic environments. 


\section{The Mechanism of Synergic Development Between Commerce Circulation and Regional Economy}

\subsection{Commerce Circulation Enhancing the Vitality of Regional Economy}

1. Commodity and capital flows

Regional economy refers to the production complex that arises from the interaction between internal factors of economic development and external conditions in a certain region. It is a regional development entity in a certain area and closely combined with the economic elements and their distribution. Regional economy reflects the objective law of economic development and the interrelationship between connotation and denotation in different regions.

At the same time, the commerce circulation can be broken down into the circulation of commodities and trade services, which achieves the value transfer from producers to consumers. In the process of this transfer, producers gain the production value in trade and business matters while consumers gain the use value of commodities. The smoothness of the commerce circulation is largely related to two vital links, the production of enterprises and the consumption of residents. On the one hand, the circulation of commodities is a prerequisite for the transformation of the productive capital of an enterprise into the products and the acquisition of productive value. Without the circulation of commodities, the production of enterprises will lack vital consumption links, and then cause the shortage of the value chains and the subsequent inability of sustain production. At the same time, consumption will also be affected by the shortage of production, resulting in lower social demand, slow economic growth and even panic in the whole society. Therefore, the commerce circulation is an important channel to open up the production of enterprises and social consumption. Especially in the era of economic globalization today, the commerce circulation also brings capital flows and thus it has risen to a fundamental position. Since the reform and opening up, China's circulation industry has made remarkable progress and a qualitative leap. Perfect logistics and information network have been established in China and the growing network is promoting the better development of regional economy.

\section{Technology and information flows}

With the continuous development of economic development, the innovation and development of the commerce circulation is also more comprehensive, which manifests as the more obvious promotion of technology and information circulation to the regional economy development. For example, in the process of building the Silk Road Economic Belt, the advanced logistics system made the cooperation and development among different regions become possible, coordinated superior resources in the eastern and western regions and created a system of interconnected and interoperable commerce. The eastern region has mature manufacturing and development modes, including better-developed manufacturing, convenient transportation and a complete system of commerce circulation. Owing to the healthy competition in the industry, the production cost of many products has obvious advantages over other regions, such as fabrics, paper making, electronic components, and so on. In this Economic Belt, industries with advanced technologies and industrialization are mainly concentrated in the western region which is also the gathering place for high-end industries. Although this region is famous for the deep industrial development but the breadth of development is not enough. The oil and other economic industries are mainly concentrated in the central region of the Silk Road Economic Belt. It mainly depends on energy exports to stimulate the economy in the short term, but there is no long-term support and the industry is rather single. The quick connection and common development of technology and information with the eastern region help the western region realize the idea "developing economy based on existing resources". Logistics network more convenient achieve the circulation and output of products and technologies, realizing the mutually benefit between the east and the west. This largely compensates for the slow development in the western region, which is characterized by abundant resources and insufficient information and manufacturing base. It also helps the eastern region better establish a complete industrial sector and achieve rapid economic development. 


\subsection{The Promotion of Regional Economy to the Commerce Circulation}

As mentioned above, the commerce circulation is not only a boost to the regional economy but also a core force for regional participation in market competition. The greater the ability of the regional commerce circulation is, the greater the value of regional industries and the economic competitiveness is in the region, which will generate more vitality factors and stronger potential forces to develop the regional economy. Implementing the business strategy and nurturing famous-brand products can promote the rapid development of industrial economy in the region. The development of the eastern region can be taken as an example here. The growing number of regional brands cultivated and grown in the eastern region in recent years has greatly enhanced the attractiveness of this region, and the growth of the fixed investments there has risen substantially, effectively boosting the growth of the regional GDP. This has made outstanding contributions to the region's fiscal revenue, solved the employment problem in the region and promoted the improvement of the residents' consumption level. Therefore, the successful construction and cultivation of regional commerce circulation system will not only enable enterprises to grow rapidly, but also optimize the allocation of regional resources and upgrade the industry level of regional development, thereby promoting the continuous upgrading of regional industries and making the regional economy develop in a healthy and rapid way. After the rapid development of the regional economy, the region has an increasingly urgent need to communicate with the neighboring cities. This will boost the rapid development of infrastructures, such as highways, railways and shipping, and thus open up channels more favorable for commerce circulation. The development of the regional economy also attracts investors in other cities or regions to keep a watchful eye on the local industrial elements or capital elements. Outside investment can enhance the regional economy and make the industrial structure more perfect and reasonable, which will have an obvious impetus to the construction of the entire commerce circulation system.

\section{How to Improve the synergetic Development of Commerce Circulation and Regional Economy from the Perspective of Symbiosis}

\subsection{To Strengthen the Concept of Symbiotic Development}

The idea of symbiotic development requires the cooperation and mutual promotion between the commerce circulation and regional economy in the same region. In the current economic development in our country, the national commerce circulation industry must truly reflect the development of the regional economy. In the future, local governments are supposed to highlight the commerce circulation, improve the economic functions embodied in it, strengthen the connection between relevant cities or economies in the symbiotic economic system and promote the import and export of commodities, so as to promote the development of the regional economy. For example, it is feasible to develop commodity economy with characteristics relying on convenient traffic conditions. Due to interconnections between the logistics channel and the commodity channel, the economic development in this region will no longer be based on the traditional offline sales, but achieve industrial restructuring and mode upgrading. Moreover, the introduction of the online sales platform which is more convenient and quick helps to facilitate the rapid circulation of goods in relevant cities or a symbiotic economy. On the one hand, consumers can enjoy cross-regional shopping with high-speed network channels and secure onshore logistics channels. On the other hand, related products and specialties in the region can also quickly enter other markets in the symbiotic economy and enrich consumers' choices. In this sense, accelerating the construction of commerce distribution channels will change the traditional one-to-one and one-to-many development modes to the one-to-many, many-to-one and many-to-many modes, thereby better promoting the mutual economic construction.

\subsection{To Enhance the Market Integration in the Symbiotic Area}

The integration of commodities and the economic market is the main mode of commercial economy currently. To control the efficiency of capital operation, the symbiotic economy should 
firmly grasp the geographical advantages and form an integrated economic market to expand the influence of the market.

The integrated market can be constructed quickly by shortening the time that the circulation of commodities takes in regions. The local government is expected to give priority to the development of tourism and tertiary industries in cities or economies with relatively a high economic level in the region, in order to promote the overall economic performance of the symbiotic economic circle. At the same time, it shall support the central city of the symbiotic economic circle and its surrounding cities to exert their respective advantages by virtue of the beneficial influence of market integration and drive the development of the regional economy.

It is needed to promote the optimization of relevant logistics policies. The construction of the symbiotic economic system has weakened regional fragmentation, removed the trading barriers and policy barriers in the relevant markets, which plays a decisive role in the realization of market integration. In the future, it is necessary to strengthen the construction of urban rapid logistics channels in the system and promote integrated market economy, which will bring great convenience to relevant enterprises and businesses.

The further establishment of the linkages among the various economies is conducive to the formation of a common economic market with complementary industries. It is bound to be able to optimize product upgrades in a region and save cost, if the dominant industries or products of cities or economies in the symbiotic economic system are sold in the market of this region. Therefore, economic exchange is an important part of each economy. It is well known that economy drives politics. In the future, the regional economy will deepen cooperation, optimize resources and form the complementarity of economic cooperation by providing conditions for different cities or economies.

\subsection{To Develop Supply Chain Management and Enhance the Modernization of Commerce Circulation}

In most areas of our country, the development of the commerce circulation industry is a transformation process from the single logistics service to a comprehensive service of logistics service and logistics management. To the commerce circulation industry which continuously emphasizes speed of development and innovation, the supply chain is a very promising development thought worth learning. The establishment of the supply chain requires the commerce circulation industry to seek long-term cooperation with logistics partners to establish a complete chain-pattern management process composed of acceptance of goods, distribution, management, delivery and other links. This will greatly facilitate the development of commerce circulation, further increasing its logistics potential.

To achieve a considerable level of supply chain management, logistics companies need to clearly define the core of their development, regard and practice the supply chain management as part of the logistics management, and then form systematic experience by continuously summarizing key points and develop critical points in practice. The ultimate purpose is to comprehensively develop and enhance the logistics market potential of the commerce circulation industry.

\section{Summary}

To sum up, from the perspective of symbiosis, the development of commerce circulation and regional economy shows significant synergies. This is manifested in the relationship featured by mutual benefit and mutual promotion between the two. Therefore, symbiosis mode based on symbiosis perspective is able to help to realize the integration of regional resources and establish a perfect infrastructure for the development of commerce circulation. At the same time, it is necessary to support and encourage the development of the regional economy with policies, so as to establish a good symbiotic economic model and achieve the smooth transition and sustainable development of our economy in this "new normal” economy. 


\section{References}

[1]. Wang Xiaoxin. Combined Development Strategy of Regional Economy and Commerce Circulation from the Perspective of Coordinated Development [J]. Journal of Commercial Economics, 2017 (24): 144-146 [2018-01-03].

[2]. Fan Xinyue. On Synergetic Development of Commerce Circulation and Regional Economy from the Perspective of Symbiosis [J]. Journal of Commercial Economics, 2017 (02): 191-193.

[3]. Yin Yujie. Research on the Collaborative Development of Regional Commerce Industry in Xiamen, Zhangzhou and Quanzhou [D]. Jimei University, 2015.

[4]. Xu Jinjin. Study of the Synergistic Development of the Commerce and Trade in West Triangle Economic Zone [D]. Chongqing Normal University, 2 